\title{
Effect of errors on miss distance of missile trackers in active decoy environment
}

\author{
E. Vijayalakshmi ${ }^{1}$, N. N. Sastry ${ }^{2}$, B. Prabhakar Rao ${ }^{3}$ \\ 'Jagan's Engineering College, India \\ ${ }^{2}$ Department of ECE, V. R. Siddhartha Engineering College, India \\ ${ }^{3}$ Department of ECE, JNTU, India
}

\section{Article Info \\ Article history: \\ Received Apr 5, 2019 \\ Revised Jun 25, 2019 \\ Accepted Jul 3, 2019}

\section{Keywords:}

Decoy

Electronic warfare

Index terms - radar

Mono pulse

\begin{abstract}
Lock on missiles are a major threat to vital installations. Soft kill solutions against lock on incoming missiles such as deployment of active decoys can be very effective to war of threat. The weaknesses in onboard missile tracking radars can be gainfully used to increase the miss distance between target and the missile. The effect of geometrical positioning errors of two horn monopulse missile mounted radars has been analyzed in this paper. As so gain differences between the two horns can cause variations in the miss distance. This aspect has also been studied. The variation of miss distance with jammer power to signal ratio $(\mathrm{J} / \mathrm{S})$ is also presented. It can be seen that the miss distance is always midway between the target and the decoy. Random angular positioning errors of the missile radar have been analyzed and it is found that the miss distance increases with increase of angular errors.
\end{abstract}

Copyright @ 2019Institute of Advanced Engineering and Science. All rights reserved.

\section{Corresponding Author:}

E. Vijayalakshmi, Jagan's Engineering College, Nellore, India.

Email: edurivijaya@gmail.com

\section{INTRODUCTION}

Friendly targets such as ships, land installations and others have to be protected against incoming lock on missiles. There are both hard kill and soft kill options available for protecting friendly ships and on-land installations. Soft kill options such as deployment of decoys have been used effectively to ward off incoming missile threats. The weaknesses in tracking radar of the missiles have been exploited quite effectively. Miss distances of missiles with active decoy deployed have been computed for various cases and reported in literature [1]. The beam pointing errors in the missile tracking radar on account of geometrical positioning errors modify the miss distance achievable for a given active decoy deployment. This aspect has been studied in detail through Mat lab simulations and reported in this paper.

An active decoy has been one of the most efficient device due to its high deception performance and low cost [2]. For the optimal design of the active decoy, modeling and simulation methods may be required to evaluate the radar jamming performance of the active decoy [3]. In [4-5], the basic requirements for distributed general purpose decoy series (DGPD) have been presented. Hyper spectral signature and corresponding transform domain analysis method has proved effective for discriminating target radiation from decoy used in practice [6]. A new anti-ARM technique using random phase and amplitude active decoys has been presented [7]. The various counter measure techniques against ARM have also been studied [8-15]. In another paper, the deceptive effect of blinking decoys on ARM s have been discussed [16]. The performance evaluation of radar and decoy system counteracting ARM has been reported [17]. 
In this paper section 2 describes deployment geometry, section 3 mathematical formulations, section 4 geometrical positioning errors, section 5 results and analysis, and section 6 conclusions. The reference paper for this analysis is the paper published by the author earlier [1].

\section{MISSILE AND DECOY GEOMETRY}

The missile and decoy geometry is shown in Figure 1. Missile is assumed to be located at the origin ' $\mathrm{o}$ '. Target is assumed to be in the terminal phase tracking the target. Hence, angle $\theta_{\mathrm{t}}$ is the subtended angle between the projection of the decoy in the X-Y plane and the target which is also located in the X-Y plane.

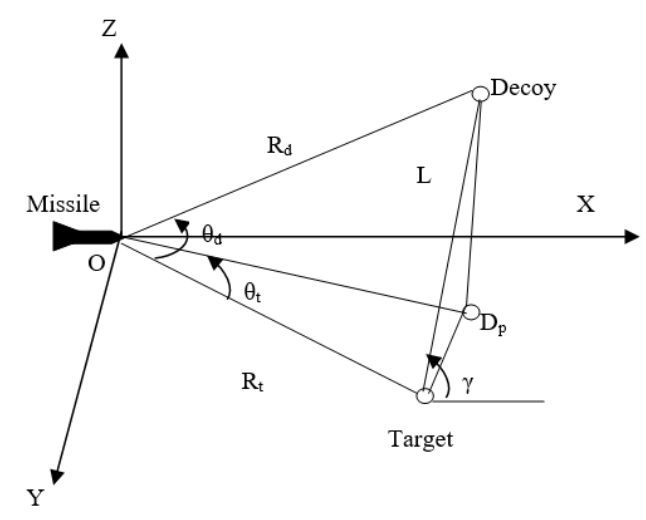

Figure 1. Missile and decoy geometry

The following are the various parameters defining the geometry. $\theta_{\mathrm{d}}$ - Angle between decoy and target subtended at the missile; $R_{d}$ - Distance between missile and the decoy in meters;

$\mathrm{R}_{\mathrm{t}}$ - Distance between missile and target in meters;

L- Distance between the decoy and target;

$\gamma$ - Angle between missile to target line and the target to decoy line.The missile has a monopulse receiver, which has an RF frontend followed by mixer, IF amplifier.

\section{MATHEMATICAL FORMULATION}

The monopulse radar is assumed to have a two horn monopulse receiving system. The antennas are squinted at $\theta_{0}$ with respect to missile to target axis, which is the bore sight. The radiation power pattern is assumed to be Gaussian in nature. The angle estimation is done with the standard sum and difference approach. The sum and difference signals are taken at the IF output. Coherent monopulse processing is assumed.Three types of errors can occur in the two horn system.

Case 1: Squint angle is changed by $\Delta \theta_{0}$.

Case 2: The gains of the antennas differ by $\Delta \mathrm{G}=|\mathrm{G} 1-\mathrm{G} 2|$, where $\mathrm{G} 1$ and $\mathrm{G} 2$ are the gains of the antennas.

Case 3: A simultaneous occurrence of case1 and case2.

In the above three cases, signal to noise ratio as observed at IF output is varied. In all the above cases miss distance between the missile and target are computed using sum and difference IF outputs.

$$
\begin{aligned}
& \mathrm{V}_{10 \mathrm{t}}=\sqrt{\left(\mathrm { S } * \mathrm { G } _ { 0 } * \operatorname { e x p } \left(-2.776 *\left(\left(\theta_{\mathrm{t}}-\theta_{0}-\Delta \theta\right) / \theta_{\mathrm{b}}\right)^{2}\right.\right.}+\mathrm{A}_{\mathrm{n}} \\
& \mathrm{V}_{1 \mathrm{t}}=\mathrm{V}_{10 \mathrm{t}} * \sin (\omega \mathrm{t}+\Delta \varphi) \\
& \mathrm{V}_{20 \mathrm{t}}=\sqrt{\left(\mathrm { S } * ( \mathrm { G } _ { 0 } + \Delta \mathrm { G } _ { 0 } ) * \operatorname { e x p } \left(-2.776 *\left(\left(\theta_{\mathrm{t}}+\theta_{0}+\Delta \theta\right) / \theta_{\mathrm{b}}\right)^{2}\right.\right.}+\mathrm{A}_{\mathrm{n}} \\
& \mathrm{V}_{2 \mathrm{t}}=\mathrm{V}_{20 \mathrm{t}} * \sin (\omega \mathrm{t}+\Delta \varphi) \\
& \mathrm{V}_{10 \mathrm{~d}}=\sqrt{\left(\mathrm { J } * \mathrm { G } _ { 0 } * \operatorname { e x p } \left(-2.776 *\left(\left(\theta_{\mathrm{d}}-\theta_{0}-\Delta \theta / \theta_{\mathrm{b}}\right)^{2}\right.\right.\right.}+\mathrm{A}_{\mathrm{n}} \\
& \mathrm{V}_{20 \mathrm{~d}}=\sqrt{\left(\mathrm { J } * ( \mathrm { G } _ { 0 } + \Delta \mathrm { G } _ { 0 } ) * \operatorname { e x p } \left(-2.776 *\left(\left(\theta_{\mathrm{d}}+\theta_{0}+\Delta \theta / \theta_{\mathrm{b}}\right)^{2}\right.\right.\right.}+\mathrm{A}_{\mathrm{n}} \\
& \mathrm{V}_{1 \mathrm{~d}}=\mathrm{V}_{10 \mathrm{~d}} * \sin (\omega \mathrm{t}+\Delta \varphi)
\end{aligned}
$$




$$
\begin{aligned}
& \mathrm{V}_{2 \mathrm{~d}}=\mathrm{V}_{20 \mathrm{~d}} * \sin (\omega \mathrm{t}+\Delta \varphi) \\
& \mathrm{V}_{1}=\mathrm{V}_{1 \mathrm{t}}+V_{1 d} \\
& \mathrm{~V}_{2}=\mathrm{V}_{2 \mathrm{t}}+V_{2 d}
\end{aligned}
$$

Where, $\mathrm{V}_{1}$ - Time domain signal voltage at IF output

$\mathrm{V}_{2}$ - Time domain signal voltage at IF output

$\mathrm{V}_{10 t}$-Amplitude of the target echo signal at horn1

$\mathrm{V}_{20 t}$-Amplitude of the target echo signal at horn2

$\mathrm{V}_{10 \mathrm{~d}}$-Amplitude of the decoy signal at the output of horn1

$\mathrm{V}_{20 \mathrm{~d}}$-Amplitude of the decoy signal at the output of horn2

S-signal power

$\mathrm{J}$-Decoy repeater power

$\Delta \phi$-Random phase of additive noise

$\mathrm{G}_{0}$ - Gain of receiving antennas1 and 2.

$\theta_{\mathrm{t}}$ - Angle between missile and target $=0$

$\theta_{0}$ - Squint angle of the horns with respect to missile-target axis

$\theta_{\mathrm{B}}$ - Half power beam width

$\omega$ - Radian frequency at IF.

$\mathrm{A}_{\mathrm{n}}$-Additive noise amplitude

$\Delta \theta$ - angular error due to antenna positioning; this is varied between 0 to 0.5 times of $\theta_{0}$.

$$
\begin{aligned}
& V_{\text {sum }}(f, \theta, t)=V_{1}+V_{2} \\
& V_{\text {diff }}(f, \theta, t)=V_{1}-V_{2}
\end{aligned}
$$

The error voltage related to angular tracking error of radar is given by

$$
\mathrm{V}_{\text {error }}(\mathrm{f}, \theta, \mathrm{t})=\operatorname{real}\left(\mathrm{V}_{\text {diff }} / \mathrm{V}_{\text {sum }}\right)
$$

Where, $\theta$ - Angle off bore sight axis of the monopulse antenna system

Simulations have been carried out for studying variation of voltage error $\mathrm{V}_{\text {error }}$ for various values of active decoy jammer power to radar echo signal ratio J/S ( as measured at receiver SUM channel IF output) against $\gamma$ and $\mathrm{L}$. Miss distance is computed using the relation,

$$
\mathrm{R}_{\mathrm{d}}^{2}=\mathrm{R}_{\mathrm{t}}^{2}+\mathrm{L}^{2}-2 \cdot \mathrm{R}_{\mathrm{t}} \cdot \mathrm{L} \cdot \cos (180-\gamma)
$$

\section{GEOMETRICAL POSITIONING ERRORS}

Computer simulations have been carried out for studying miss distance by considering the errors caused by the above three cases. Since during manufacture and assembly squint angle errors are bound to occur and these errors modify the miss distance significantly. Hence, the squint angle $\theta_{0}$ is taken as $\theta_{0} \pm \Delta \theta$, where $\Delta \theta$ is the random squint angle error. $\Delta \theta$ is assumed to vary up to $50 \%$ of $\theta 0$. The variation of $\theta 0$ with errors is assumed to follow Gaussian distribution. In computer simulations, this aspect is taken into account. Since $\theta_{0}+\Delta \theta$ is made a random variable, miss distance is computed for every value of $\theta 0+\Delta \theta$, mean of miss distance is obtained and plotted. This has been done for all the four cases cited above. Further, in each case, gamma and SNR have also been varied and average and standard deviation of miss distance is obtained. Various parameters affecting deployment have been studied and, mean also calculated. For various values of $\gamma$ ranging from 100 to 1700 , miss distance varies in accordance with the gain. That is, as gain decreases miss distance also decreases. The ranges of the parameters which are used in computer simulations are given below. Miss distance $\mathrm{D}$ versus $\mathrm{J} / \mathrm{S}$ is also computed (Miss Distance is the distance between target and the missile nearest to the target in the presence of decoy).

$\begin{array}{lll}\mathrm{J} / \mathrm{S} & - & 0 \text { to } 30 \\ \gamma & - & 10^{0} \text { to } 170^{\circ} \\ \mathrm{L} & - & 100 \text { to } 600 \text { meter. } \\ \mathrm{R}_{\mathrm{t}} & - & 10 \mathrm{Km} . \\ \mathrm{G}_{0} & - & 0.7 \text { to } 1 . \\ \Delta \theta & - & 0 \text { to } 30 \% \text { of } \theta_{\mathrm{B}} .\end{array}$


The above has been repeated with a typical IF SNR of $5 \mathrm{~dB}, 10 \mathrm{~dB}$ and without noise. From the voltage error, the angular error produced by the monopulse system which is calibrated for tracking with a single target has been computed and miss distance in meter is plotted. These are shown in Figure 2. The effects of antenna errors when the latter are nil and at different values on miss distances have been calculated and notified. The mean values of miss distance have been calculated in the conditions the gamma angle from $60^{\circ}$ to $120^{\circ}$ and $\mathrm{L}$ from 100 to 600 meter separately for the deployment of decoy and these values for the gamma $60^{\circ}$ and $70^{\circ}$ are notified in the tables shown in Tables1-2.

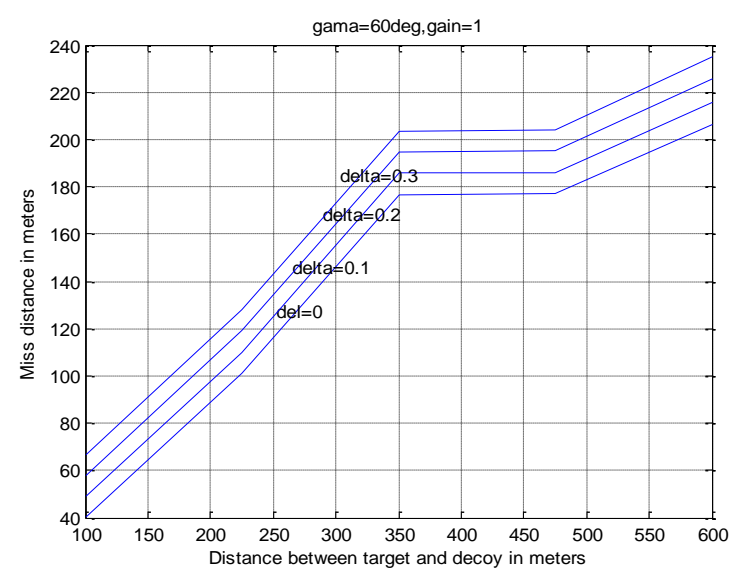

Figure 2. Miss distance variation with $\mathrm{L}$, (without additive noise) at $\gamma=60^{\circ}$, $\mathrm{R}_{\mathrm{t}}=10 \mathrm{Km}$; Antenna error $(\Delta \theta)$ is $0,0.1,0.2,0.3$

Table 1. Mean of miss distance at $\gamma=60^{0}$

\begin{tabular}{cccccc}
\hline Mean of $\Delta \theta$ & \multicolumn{5}{c}{ Mean of Miss distance at $\gamma=60^{\circ}$} \\
& $L=100 m$ & $L=225 m$ & $L=350 m$ & $L=475 m$ & $L=600 m$ \\
\hline 0.05 & 37.819 & 96.303 & 186.437 & 158.641 & 183.824 \\
0.15 & 44.1633 & 102.662 & 192.388 & 165.303 & 190.66 \\
0.25 & 47.108 & 105.630 & 195.159 & 168.4 & 193.84 \\
0.35 & 50.192 & 108.744 & 198.048 & 171.632 & 197.161 \\
0.45 & 56.44 & 115.014 & 203.906 & 178.183 & 203.90 \\
\hline
\end{tabular}

Table 2. Mean of miss distance at $\gamma=70^{\circ}$

\begin{tabular}{cccccc}
\hline Mean of $\Delta \theta$ & \multicolumn{5}{c}{ Mean of Miss distance at $\gamma=70^{0}$} \\
& $L=100 m$ & $L=225 m$ & $L=350 m$ & $L=475 m$ & $L=600 m$ \\
\hline 0.05 & 42.909 & 85.3548 & 252.891 & 199.965 & 232.379 \\
0.15 & 50.687 & 93.2227 & 259.393 & 208.208 & 241.057 \\
0.25 & 55.480 & 98.0690 & 263.478 & 213.285 & 246.390 \\
0.35 & 58.440 & 101.059 & 266.046 & 216.413 & 249.668 \\
0.45 & 63.863 & 106.537 & 271.111 & 222.132 & 255.682 \\
\hline
\end{tabular}

\section{SIMULATIONS AND RESULTS}

The gamma values are fixed varying from 600 to 1200 and fixing the antenna angular errors from 0 to 0.5 for the calculations of miss distances. Fixing the antenna error as $0, \gamma=600$, the variations of miss distance with $\mathrm{J} / \mathrm{S}$ have been simulated for the values of $\mathrm{L}$ varying from 100 to $600 \mathrm{~meter}$. The above simulation has been carried out for different values of $\gamma$ from 700 to 1200 are shown in the Figures 3-5. If $\mathrm{J} / \mathrm{S}$ ratios are less than 5 , it is identified that the curves are not steady. When the decoy is deployed to a distance of $\mathrm{L}=600$ meter, from the deck of the ship, and at an angle of $\gamma=1100$, with no antenna error, and at the noise of $5 \mathrm{~dB}$, the calculated miss distance is found to be between $300 \mathrm{~m}$ and $400 \mathrm{~m}$. The decoy deployment is repeated at the same angle and same distance as above with no noise and with no antenna error, the miss distance has found to be $200 \mathrm{~m}$ to $250 \mathrm{~m}$. The mean of miss distance against angular error due to antenna positioning for different $\gamma$ values is calculated at every L separately. The above simulation has been carried out for $\mathrm{J} / \mathrm{S}=1, \mathrm{~J} / \mathrm{S}=5$ and the graphs are shown in Figures 6-11. 


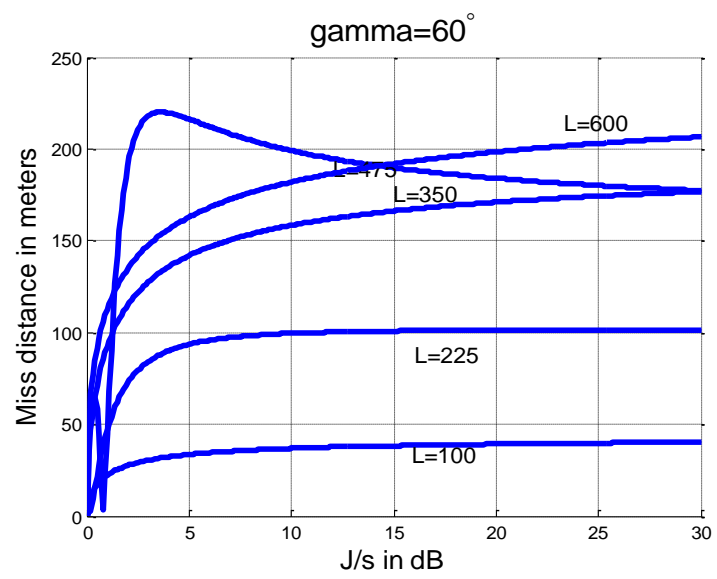

Figure 3. Miss Distance variation with $\mathrm{J} / \mathrm{S}$, antenna positioning angular error is 0 , (without additive noise) at $\gamma=60^{\circ}, \mathrm{R}_{\mathrm{t}}=10 \mathrm{Km}$; $\mathrm{L}$ is 100 to 600 meter

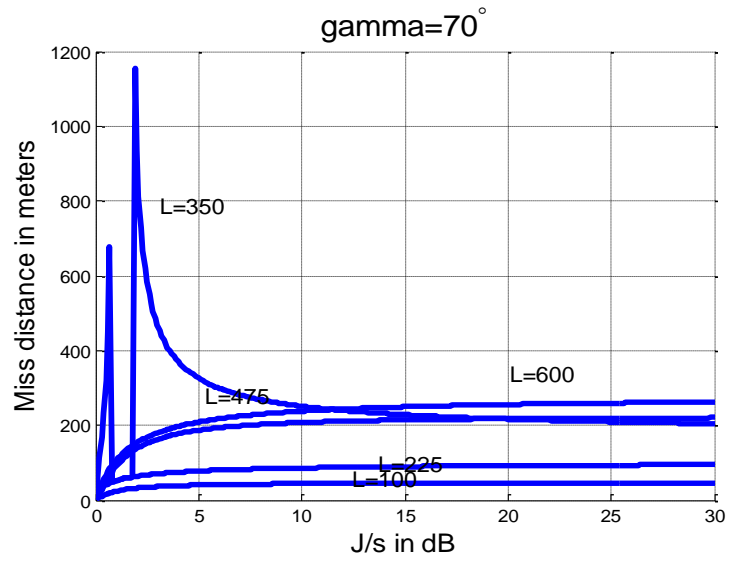

Figure 4. Miss Distance variation with J/S, antenna positioning angular error is 0 , (without additive noise) at $\gamma=70^{\circ}, \mathrm{R}_{\mathrm{t}}=10 \mathrm{Km}$; $\mathrm{L}$ is 100 to 600 meter

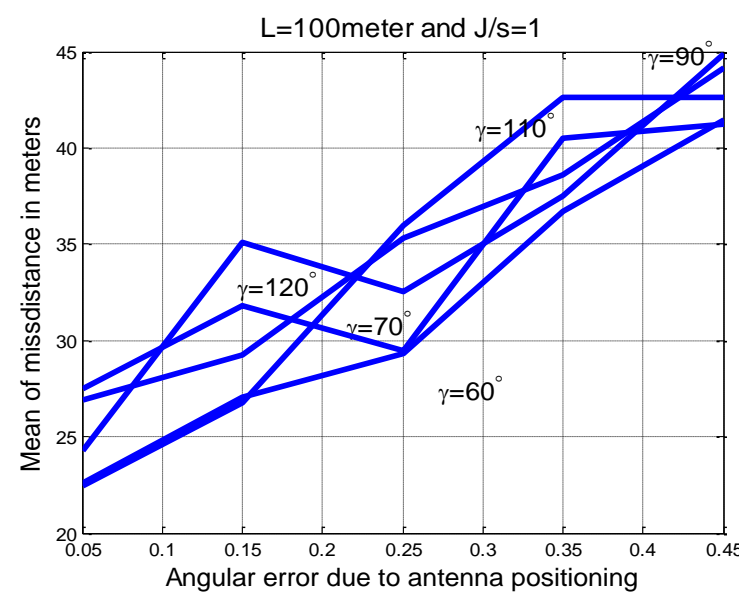

Figure 6. Mean of miss Distance variation with antenna positioning angular error (without additive noise) at $\mathrm{L}=100$ meter, $\mathrm{J} / \mathrm{S}=1, \gamma=60^{0}$ to $120^{\circ} ; \mathrm{R}_{\mathrm{t}}=10 \mathrm{Km}$

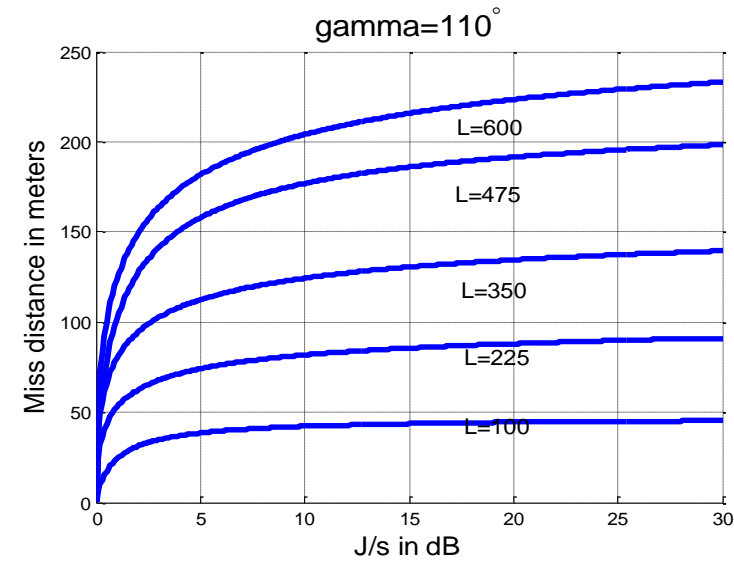

Figure 5. Miss Distance variation with J/S, antenna positioning angular error is 0 , (without additive noise) at $\gamma=60^{\circ}, \mathrm{R}_{\mathrm{t}}=10 \mathrm{Km}$; $\mathrm{L}$ is 100 to 600 meter

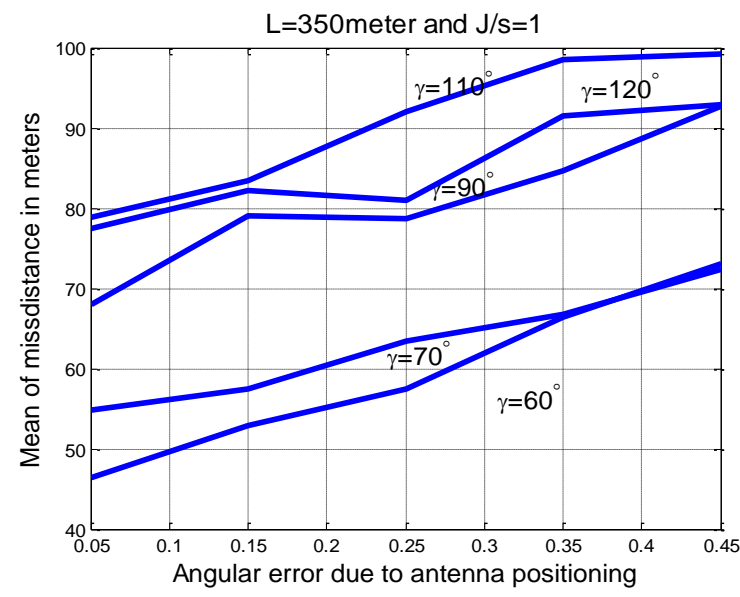

Figure 7. Mean of miss Distance variation with antenna positioning angular error (without additive noise) at $\mathrm{L}=350$ meter, $\mathrm{J} / \mathrm{S}=1, \gamma=60^{\circ}$ to $120^{\circ} ; \mathrm{R}_{\mathrm{t}}=10 \mathrm{Km}$ 


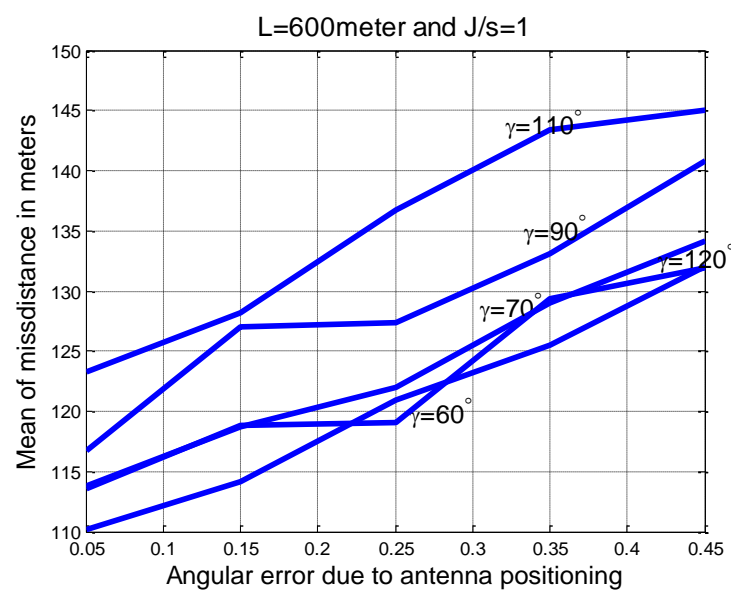

Figure 8. Mean of miss Distance variation with antenna positioning angular error (without additive noise) at $\mathrm{L}=600$ meter, $\mathrm{J} / \mathrm{S}=1, \gamma=60^{\circ}$ to $120^{\circ} ; \mathrm{R}_{\mathrm{t}}=10 \mathrm{Km}$

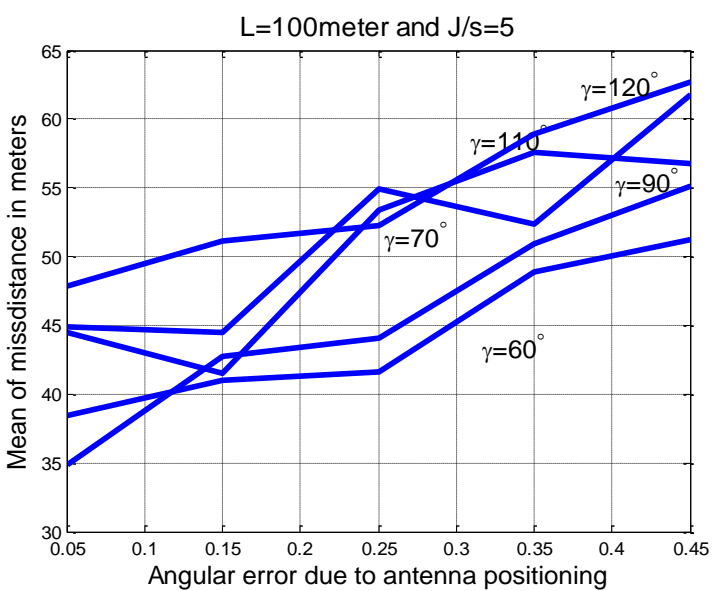

Figure 9. Mean of miss Distance variation with antenna positioning angular error (without additive noise) at $\mathrm{L}=100$ meter, $\mathrm{J} / \mathrm{S}=5, \gamma=60^{\circ}$ to $120^{\circ} ; \mathrm{R}_{\mathrm{t}}=10 \mathrm{Km}$

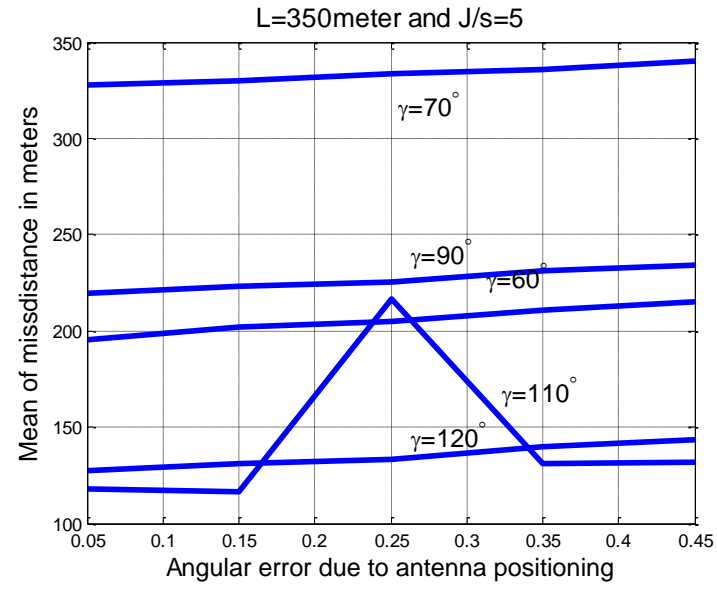

Figure 10. Mean of miss Distance variation with antenna positioning angular error (without additive noise) at $\mathrm{L}=350$ meter, $\mathrm{J} / \mathrm{S}=5, \gamma=60^{\circ}$ to $120^{\circ} ; \mathrm{R}_{\mathrm{t}}=10 \mathrm{Km}$

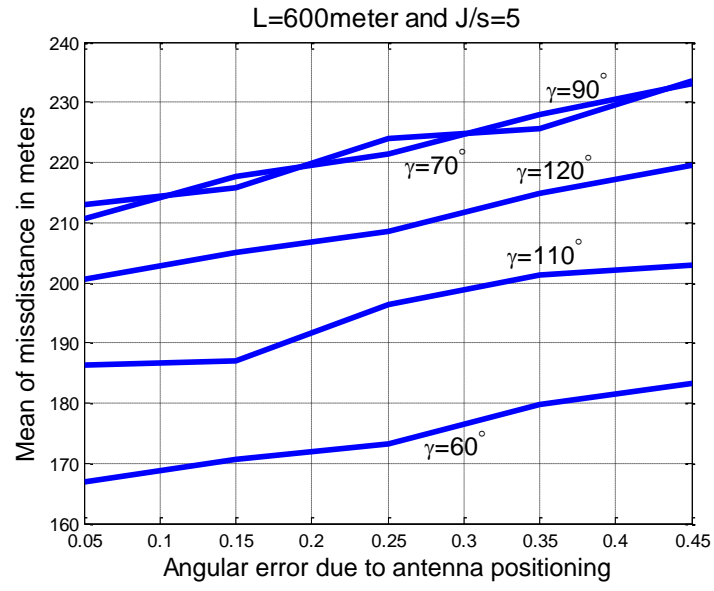

Figure 11. Mean of miss Distance variation with antenna positioning angular error (without additive noise) at $\mathrm{L}=600$ meter, $\mathrm{J} / \mathrm{S}=5, \gamma=60^{\circ}$ to $120^{\circ} ; \mathrm{R}_{\mathrm{t}}=10 \mathrm{Km}$

\section{CONCLUSION}

Decoys have been used extensively as soft kill options against the threat of incoming missiles. Two horn monopulse missile radar system has been analyzed for computing miss distance between target and the decoy. Variation of miss distance with $\mathrm{J} / \mathrm{S}$ ratio and receiver noise has been analyzed and results reported. It has been found that a $\mathrm{J} / \mathrm{S}$ ratio of $5 \mathrm{~dB}$ is required for stable operation of active decoys, without considering geometrical antenna errors. Angular error has been taken as a random variable and effect of this parameter on miss distance is analyzed. It can be seen that miss distance increases with antenna positioning angular errors. Therefore, it is essential that the antenna angular errors should be kept to a minimum for reducing the miss distance from the missile standpoint of view and it is beneficial for the friendly target if the missile antenna positioning errors are more.

\section{ACKNOWLEDGEMENTS}

The authors gratefully acknowledge the constant encouragement given to our work by Dr. A. V. Ratnaprasad, Principal, V. R. Siddhartha Engineering College, Vijayawada. 


\section{REFERENCES}

[1] E. Vijayalakshmi, Dr. N. N. Sastry, Dr.b.Prabhakarrao, "Optimum active decoy deployment for effective deception of missile radars,"Proc. IEEE CIE International conference on radar, vol1, page(s) 234-237, Oct 2011.

[2] F. Neri, "Introduction to electronic defense systems," Artech house, London, 1991.

[3] "Jamming performance analysis for repeater active decoy against ground tracking radar considering dynamics of platform and decoy," The $18^{\text {th }}$ international radar symposium IRS 2017, June, 2017.

[4] "Anti-ARM technique: Distributed general purpose decoy series (DGPD)," 2001 IEEE, 306-309.

[5] Nahumgal, Jacobbarhen, Sandeepgulati and Capt.todd D. Steiner, "Hyper spectral Air-to-Air seeker," Proc.SPIE 2231, 127-135 (1994).

[6] "Airborne target tracking algorithm against oppressive decoys in infrared decoys in infrared imagery," Proc.of SPIE vol.7495.

[7] MajidEmadi, Amirjafargholi, M. H. S Moghadam and FarokhMarvasti, "New Anti-ARM Technology by using random phase and amplitude active decoys,’PIER 87, pp. 297-311,2008.

[8] Fan Zhenqin, Wang Yongjie, Li Bo, Liu Heng, "Research on three source layout of active decoy against ARM," International symposium on computers \& informaticas (ISCI 2015) on page(s) 1480-1487, 2015.

[9] Samuel. M. Sharman, "Monopulse principles and techniques," page 205, Artech house.

[10] E. L. Srujana and Dr. N.N. Sastry, "Noise interference effects in unbalanced monopulse receiver channels," IETE Journal of research, vol. 54,no2,pp 169-174, Mar-Apr 2008.

[11] Kilger IE and Olenberger CE, "Multiple target effects on monopulse signal processing," IEEE AES-11, pp. 165,795-804, Sept 1975.

[12] Testuro Endo, "Analysis of interfere effects on monopulse radars,"IEEE Transactions on AES vol.24, no 6, Nov 1988.

[13] Li.N, "Radar ECCM's new area: Anti-stealth and anti-ARM,"IEEE transactions on aero space and electronic systems, vol.31, no.3, July 1995.

[14] Lian. W, "Discussion of radar anti anti-radiation missile technology-alarming plus decoy system,"International radar conference, CIE 2001, 2001.

[15] Wang. F, R. He, and X. Sha, "Anti-ARM technique: Feature analysis of ARM warning radar," International radar conference, CIE2001, 2001.

[16] Dong Wen-feng, Liu, Quancheng, Zhong-kuan, and Pan Zi-kai, "The deceptive effect of blinking decoys on ARMs," ICAIC2011, Part I, CCIS 224, pp.338-347, 2011.

[17] Weiguangzhoujirunluo, Yuguijiahuabinwang, "Performance evaluation of radar and decoy system counteracting anti radiation missile,"IEEE transactions on aerospace and electronic systems, vol.47, no.3, July 2011.

\section{BIOGRAPHIES OF AUTHORS}

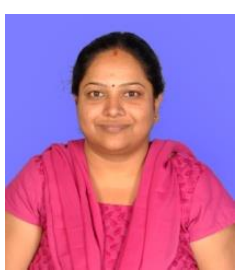

Mrs. E. Vijayalakshmi was born in 1978 in Andhra Pradesh. She got her Bachelor's degree from JNT University, Anantapur in 2001. Master's degree from JNT University, Kakinada in 2005. She joined as a Lecturer in Nova Engineering college, W.G.Dist, A. P. in 2002 and became Associate Professor in Priyadarshini Institute of technology, Nellore, A. P. in April 2013.She has been pursuing her $\mathrm{PhD}$ since 2010 at JNT University, Kakinada.

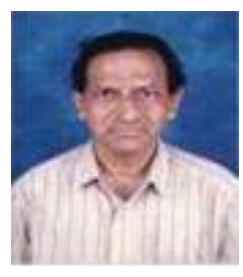

Dr. N. N. Sastry was born on 15 Sep 1945 in Andhra Pradesh in India. He got his Bachelor's degree in Electronics and Communications Engineering from Indian institute of Sciences, Bangalore in 1967, Master degree from JNT University, Hyderabad in 1979, and PhD from Osmania University in statistical signal processing in 1995. He worked in Defence Electronics Research Laboratory DLRL, DRDO, Min. of Defence for over 38 years since 1968. He was the associate program director of a very massive, successful Army-DRDO program called SAMYUKTA. He is at present working as a Professor at VR Siddhartha engineering college, Vijayawada, Andhra Pradesh.. His areas of interest are Antennas, Microwaves, EW and Radar systems. He published many papers in National and International journals, Conferences and brought out over 100 technical reports.

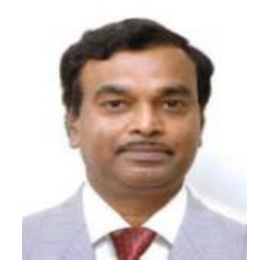

Dr. B. Prabhakarrao was born in the year 1955 at Buchireddypalem, Nellore, and Andhra Pradesh. He did B.Tech and M.Tech from SV University, Tirupati with specializations in Electronics and communication engineering, Electronic Instrumentation and communication systems in the years 1979 and 1981 respectively. He obtained his doctoral degree from Indian institute of science, Bangalore, in the area of sonar signal processing in the year 1955. Dr. Rao joined as Assistant professor in JNT University in the year 1982. He became Professor in ECE Dept. in the year 2003. His current areas of research interest are Optical, Wireless, Microwave and Digital communications, Coding and Image processing. 